\title{
Erratum to: Complementary photothermal techniques for complete thermal characterization of porous and semi-transparent solids
}

\author{
D. Dadarlat $\cdot$ M. Streza $\cdot$ O. Onija • \\ C. Prejmerean $\cdot$ L. Silaghi-Dumitrescu • \\ N. Cobirzan · K. Strzałkowski
}

Published online: 6 December 2014

(c) Akadémiai Kiadó, Budapest, Hungary 2014

\section{Erratum to: J Therm Anal Calorim \\ DOI 10.1007/s10973-014-4091-x}

In acknowledgements, "PN-II-PT-PCCA-2-11-3" should be replaced with "PN-II-PT-PCCA-2011-3.2-1419".

The online version of the original article can be found under doi:10.1007/s10973-014-4091-x.

D. Dadarlat · M. Streza $(\bowtie) \cdot$ O. Onija

National Institute for Research and Development of Isotopic and Molecular Technologies, 65-103 Donath Str,

400293 Cluj-Napoca, Romania

e-mail: streza.mihaela@gmail.com

C. Prejmerean · L. Silaghi-Dumitrescu

"Raluca Ripan"' Institute for Research in Chemistry,

400294 Cluj-Napoca, Romania

\section{N. Cobirzan}

Department of Civil Engineering and Management, Faculty of Civil Engineering, Technical University of Cluj Napoca, 25 G. Baritiu Street, 400027 Cluj-Napoca, Romania

\section{K. Strzałkowski}

Institute of Physics, Faculty of Physics, Astronomy and Informatics, Nicolaus Copernicus University, Grudziadzka 5, 87-100 Torun, Poland 